airway, and use of bag/mask resuscitators such as AMBU and LAERDAL; and 'Tertiary Measures,' being endotracheal intubation, ECG monitoring and defibrillation, drugs and IV infusion (the technique of setting up an infusion is not given and the description of sodium bicarbonate dosage may leave some readers in the dark).

There is a brief discussion of aftercare and future developments in CPR.

Appendices include the 'Treatment of Choking' by back blows and Heimlich technique, the 'Recovery Position,' 'Endotracheal Intubation'-described in greater detail with clear photographs and diagrams, 'Hypothermia,' 'Paediatric Resuscitation,' including the ABC of Resuscitation, Defibrillation and Drugs, and 'ECG Recognition' of several rhythms (the point about relating the ECG monitor to the patient is very valid).

At $£ 3.25$ this book is reasonably priced. Ambulance personnel involved in advanced training (as well as nurses and junior doctors) will find this book of interest, and should find the sections on endotracheal intubation, drugs and ECG recognition particularly helpful, the book being a useful addition to their bookshelf.

\author{
ALAN WATKINSON \\ Advanced Ambulance Training Scheme, \\ Stockport, \\ England
}

\title{
A Colour Atlas of Cardiopulmonary Resuscitation Techniques
}

By C. Page, K. Mills \& R. Morton

Wolfe Medical Publications Limited, London. 1986. £9.95.

There is something immediately attractive and striking about bold colour plates and colour atlases always enjoy a wide popularity. Regrettably, Cardiopulmonary Resuscitation Techniques comes far short of the high standards normally entertained by Wolfe Medical Publications. To start with, the scope of the book is confusing-the care of patients with in-dwelling tracheal tubes is no more a CPR technique than the control of bleeding from a simple scalp wound or helicopter transportation of the injured: all have very pretty and entertaining photographs but little relevance to the topic. The authors have no especial standing as experts in this field and, hence, their approach is outdated, illogical and unclear. It is at variance with current nationally and internationally agreed guidelines. Several of the illustrations are of poor technical quality or obviously faked. What is most objectionable about the book is that it purports to be all things to all men, yet the core material is treated with nothing like the right level of thoroughness. Bronchoscopy, tracheostomy, drainage of a haemothorax and open-chest cardiac compression are treated under basic life support (!) in the same glib manner as the treatment of croup in children and the use of a floatation bag in acquatic rescue.

CPR techniques can only be learned by practical supervision under the watchful eye of a skilled tutor: the disclaimer 'that certain advanced procedures shown in this atlas should only be undertaken by people trained in the techniques' would appear to make the justification for this publication a nonsense. The book falls far wide of the authors' aim 'to simplify the understanding of and improve the performance of cardipulmonary resuscitation techniques.' Because this is a picture book and realistically priced, I am 
sure that it will sell well, however unfavourable the reviews. For the discerning reader i cannot, with any seriousness, be recommended.

ANDREW K. MARSDEN

Consultant in Emergency Medicine,

Pinderfield's Hospital,

Wakefield, England

Chairman,

Resuscitation Council (UK) 